NASA/TM-2002-211574

\title{
Low-Current, Xenon Orificed Hollow Cathode Performance for In-Space Applications
}

Matthew T. Domonkos and Michael J. Patterson

Glenn Research Center, Cleveland, Ohio

Alec D. Gallimore

University of Michigan, Ann Arbor, Michigan 
Since its founding, NASA has been dedicated to the advancement of aeronautics and space science. The NASA Scientific and Technical Information (STI) Program Office plays a key part in helping NASA maintain this important role.

The NASA STI Program Office is operated by Langley Research Center, the Lead Center for NASA's scientific and technical information. The NASA STI Program Office provides access to the NASA STI Database, the largest collection of aeronautical and space science STI in the world. The Program Office is also NASA's institutional mechanism for disseminating the results of its research and development activities. These results are published by NASA in the NASA STI Report Series, which includes the following report types:

- TECHNICAL PUBLICATION. Reports of completed research or a major significant phase of research that present the results of NASA programs and include extensive data or theoretical analysis. Includes compilations of significant scientific and technical data and information deemed to be of continuing reference value. NASA's counterpart of peerreviewed formal professional papers but has less stringent limitations on manuscript length and extent of graphic presentations.

- TECHNICAL MEMORANDUM. Scientific and technical findings that are preliminary or of specialized interest, e.g., quick release reports, working papers, and bibliographies that contain minimal annotation. Does not contain extensive analysis.

- CONTRACTOR REPORT. Scientific and technical findings by NASA-sponsored contractors and grantees.
- CONFERENCE PUBLICATION. Collected papers from scientific and technical conferences, symposia, seminars, or other meetings sponsored or cosponsored by NASA.

- SPECIAL PUBLICATION. Scientific, technical, or historical information from NASA programs, projects, and missions, often concerned with subjects having substantial public interest.

- TECHNICAL TRANSLATION. Englishlanguage translations of foreign scientific and technical material pertinent to NASA's mission.

Specialized services that complement the STI Program Office's diverse offerings include creating custom thesauri, building customized data bases, organizing and publishing research results ... even providing videos.

For more information about the NASA STI Program Office, see the following:

- Access the NASA STI Program Home Page at http://www.sti.nasa.gov

- E-mail your question via the Internet to help@sti.nasa.gov

- Fax your question to the NASA Access Help Desk at 301-621-0134

- Telephone the NASA Access Help Desk at 301-621-0390

- Write to: NASA Access Help Desk NASA Center for AeroSpace Information 7121 Standard Drive Hanover, MD 21076 
NASA/TM-2002-211574

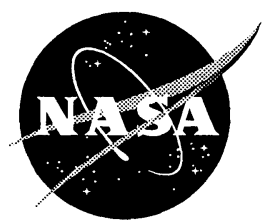

\section{Low-Current, Xenon Orificed Hollow Cathode Performance for In-Space Applications}

Matthew T. Domonkos and Michael J. Patterson

Glenn Research Center, Cleveland, Ohio

Alec D. Gallimore

University of Michigan, Ann Arbor, Michigan

National Aeronautics and

Space Administration

Glenn Research Center

July 2002 
Available from

NASA Center for Aerospace Information 7121 Standard Drive

Hanover, MD 21076
National Technical Information Service 5285 Port Royal Road Springfield, VA 22100

Available electronically at http:/ / gltrs.grc.nasa.gov/GLTRS 


\title{
Low-Current, Xenon Orificed Hollow Cathode Performance for In-Space Applications
}

\author{
Matthew T. Domonkos and Michael J. Patterson \\ National Aeronautics and Space Administration \\ Glenn Research Center \\ Cleveland, Ohio 44135 \\ Alec D. Gallimore \\ Plasmadynamics and Electric Propulsion Laboratory (PEPL) \\ The University of Michigan \\ Ann Arbor, Michigan 48109
}

\begin{abstract}
Summary
An experimental investigation of the operating characteristics of 3.2-mm diameter orificed hollow cathodes was conducted to examine low-current and low flow rate operation. Cathode power was minimized with an orifice aspect ratio of approximately one and the use of an enclosed keeper. Cathode flow rate requirements were proportional to orifice diameter and the inverse of the orifice length. The minimum power consumption in diode mode was $10-\mathrm{W}$, and the minimum mass flow rate required for spotmode emission was approximately $0.08-\mathrm{mg} / \mathrm{s}$. Cathode temperature profiles were obtained using an imaging radiometer, and conduction was found to be the dominant heat transfer mechanism from the cathode tube. Orifice plate temperatures were found to be weakly dependent upon the flow rate and strongly dependent upon the current.
\end{abstract}

\section{Nomenclature}

$$
\begin{array}{ll}
\mathrm{AR} x & =\text { cathode with an orifice aspect ratio of } x \\
\mathrm{D}_{\mathrm{O}} & =\text { orifice diameter, } \mathrm{m} \\
\mathrm{L}_{\mathrm{o}} & =\text { orifice length, } \mathrm{m} \\
\mathrm{R} & =\text { orifice radius, } \mathrm{m} \\
\mathrm{SSPC} & =\text { Space Station Plasma Contactor } \\
\mathrm{x} & =\text { orifice aspect ratio }
\end{array}
$$

\section{Introduction}

While state-of-the-art electric propulsion systems provide a systems mass advantage compared with chemical thrusters for stationkeeping and primary propulsion applications on satellites with several kilowatts of power generation, a need remains for performance improvements in sub-kilowatt propulsion systems for small satellites (ref. 1). The performance of sub-500 W ion and Hall thrusters depends heavily upon the power and propellant consumed by the hollow cathode neutralizer (ref. 1); the cathode in the Hall thruster performs the functions of both main discharge cathode and beam neutralizer. Patterson and Oleson (ref. 1) reported that a state-of-the-art neutralizer for a 100-W ion thruster could degrade the 
efficiency by up to 20 percent and reduce the specific impulse by as much as $2000 \mathrm{sec}$. Optimization of low-current hollow cathodes is also sought for plasma contactor applications. In general, spacecraft application of hollow cathode technology demands minimization of power and propellant consumption while maintaining lifetime of several years demonstrated by state-of-the-art devices used in ion thrusters and for the International Space Station. In order to develop design tools, an initial experimental investigation was conducted using laboratory model cathodes to determine the similarities and differences of low-power hollow cathode operation with previous studies (refs. 2 to 4). This article reports the results of the experimental investigation of laboratory model 3.2-mm diameter orificed hollow cathodes for low-current applications.

\section{Background}

Orificed hollow-cathode technology, used extensively in ion thrusters since the late 1960's, was brought to flight level maturity with xenon propellant as part of the International Space Station program (refs. 5 and 6). During the hollow cathode life validation program, assembly and operating procedures were developed which enabled operation in a DC discharge to $28000 \mathrm{hr}$ (ref. 6). The major operating procedures which led to the extended life of the cathode are a prescribed operating temperature regime and maintenance of electron emission in spot-mode. Operation at orifice plate temperatures below $1300{ }^{\circ} \mathrm{C}$ was chosen as an operational limit for these experiments to be consistent with practices proven to enable lifetimes greater than $10000 \mathrm{hr}$ (ref. 5). The cathode tip temperature has been considered the most representative and readily observable temperature that relates to the insert temperature (ref. 3). If the temperature is too high, the barium in the insert evaporates more quickly than it can be replenished through diffusion, and the discharge becomes unstable; low temperatures are insufficient to drive the diffusion of barium and barium oxide at a rate that sustains the low work function surface of the emitter (ref. 7). Since the lower limit represents a nondestructive condition, the cathodes in this investigation were operated at as low of an orifice plate temperature as stable operation permitted.

Spot and plume-modes are the two major electron emission regimes generally considered in orificed hollow cathode design. Spot-mode emission is characterized by a low coupling voltage to an anode, negligible AC components of the discharge voltage and current, and a bright plasma spot at the cathode orifice plate. Conversely, plume-mode emission is characterized by a somewhat increased coupling voltage to an anode, large $\mathrm{AC}$ components of the discharge voltage and current, and a distributed plasma plume downstream of the cathode. The phenomena comprising plume-mode emission lead to increased wear on the cathode orifice plate due to energetic ion bombardment. The life-limiting nature of plume-mode emission led to the decision to operate the plasma contactor in spot-mode, and the success of the $28000 \mathrm{hr}$ hollow cathode life-test validated this design decision; the cathode failure was attributed to depletion of the available barium and barium-oxide in the insert, while the orifice plate wear was modest.

\section{Experimental Apparatus}

Since the lifetime of orificed hollow cathodes is achieved through known operating and design considerations, the present investigation focused on improvements in the power and propellant consumption of low-current devices. The hollow cathodes used in this investigation were designed and fabricated based on existing hollow cathode and plasma contactor procedures (ref. 8). Since the cathodes were laboratory models, a number of the specifications and inspection procedures required for flight hardware were either relaxed or omitted. The authors attempted to follow the flight hardware procedures when it was reasonable to do so, in order to facilitate the transition from laboratory models to flight units. 


\section{Hollow Cathode Design}

An engineering schematic of the 3.2-mm diameter hollow cathodes is presented in figure 1 , and the identifying characteristics of the various cathodes tested are listed in table 1 . The orifice diameter for the AR6-A and AR6-B cathodes was chosen based on the Kaufman criterion of $12 \mathrm{~A} / \mathrm{mm}$ of orifice diameter, and the dimensions reported in this work are normalized to the diameters of AR6-A and AR6-B (ref. 9). The orifice length was chosen by combining machining considerations with numerical results obtained from the model by Mandell and Katz (ref. 10). The resulting orifice had a length-to-diameter $\left(\mathrm{L}_{\mathrm{o}} / \mathrm{D}_{\mathrm{o}}\right)$ aspect ratio of approximately six, and the two cathodes made with this type of orifice are referred to as AR6-A and AR6-B. Cathodes with orifice aspect ratios of approximately three (AR3-A) and one (AR1) were also constructed. A cathode with an aspect ratio of three (AR3-B) was constructed with an orifice diameter sixty percent that of the AR6 cathodes, and hence lower current carrying capability. Finally, a third cathode with orifice plate dimensions identical to the AR6 cathodes was constructed for tests in both enclosed (EK6) and open keeper (OK6) configurations; an enclosed keeper consists of a cylindrical tube with an orifice plate which houses the cathode. The keeper orifice diameter and gap were held constant in this investigation at normalized values of 17.6 and 7.7 orifice diameters, respectively. The inserts used in this investigation were commercially available low-work function emitters made of porous tungsten impregnated with a 4:1:1 molar ratio of $\mathrm{BaO}-\mathrm{Al}_{2} \mathrm{O}_{3}-\mathrm{MgO}$ (ref. 5). The normalized inner diameter and length were 9.4 and 98 , respectively.

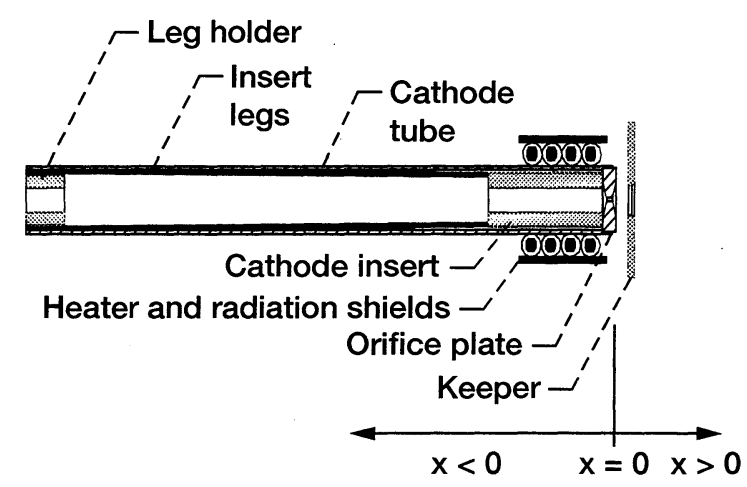

Figure 1.-Detailed schematic of the laboratory model cathodes.

TABLE 1.-CATHODE GEOMETRY AND CONFIGURATION (ORIFICE PLATE DIMENSIONS NORMALIZED BY THE AR6 ORIFICE DIAMETER)

\begin{tabular}{|l|c|c|c|c|}
\hline Cathode & $\begin{array}{c}\text { Normalized } \\
\text { Orifice Diameter }\end{array}$ & $\begin{array}{c}\text { Normalized } \\
\text { Orifice Length }\end{array}$ & Keeper Type & Secondary Anode \\
\hline AR6-A & 1.0 & 5.6 & Open & No \\
\hline AR6-B & 1.0 & 5.6 & Open & No \\
\hline AR3-A & 1.0 & 3.2 & Open and Mesh & $\begin{array}{c}\text { Yes, for plasma } \\
\text { property tests }\end{array}$ \\
\hline AR3-B & 0.6 & 1.8 & Open & No \\
\hline AR1 & 1.0 & 1.4 & Open & No \\
\hline OK6 & 1.0 & 5.6 & Open & No \\
\hline EK6 & 1.0 & 5.6 & Enclosed & Yes \\
\hline
\end{tabular}




\section{Facilities}

All of the facilities used in this investigation were cryopumped with base pressures in the high- $10^{-6}$ Pa range. During cathode operation, the tank pressure in the facilities varied from 3 to $11 \times 10^{-3} \mathrm{~Pa}$. In each case, high purity xenon was supplied to the cathode through a flow system accurate to within $\pm 7-\mu \mathrm{g} / \mathrm{s}$ based upon bubble flow-meter calibrations.

\section{Cathode Performance}

When attempting to assess experimentally the effects of varying the orifice geometry on the performance of hollow cathodes, the ideal technique is to change only the orifice plate. This was done by Siegfried (ref. 2), using a slide valve with three orifice geometries. The experiment was conducted on a mercury hollow cathode, and the aspect-ratios $\left(\mathrm{L}_{\mathrm{o}} / \mathrm{D}_{\mathrm{o}}\right)$ of the orifices were negligibly small in comparison with those considered in the current investigation. In the present investigation, separate assemblies were fabricated and tested so that the cathodes could be easily integrated with thrusters to evaluate system performance. In order to validate that the observed changes in performance were due to orifice geometry changes, it was necessary examine the operating variance between cathodes fabricated to identical specifications.

For reference, the work on the Space Station plasma contactor (SSPC) has demonstrated variances of $\pm 0.5-\mathrm{V}$ above $0.7-\mathrm{mg} / \mathrm{s}$ of $\mathrm{Xe}$, increasing to approximately $\pm 1.0-\mathrm{V}$ around $0.5-\mathrm{mg} / \mathrm{s}$ (ref. 8 ). The flow rate where the spot-to-plume mode transition occurred appeared to be invariant (ref. 8). Sarver-Verhey (ref. 6) demonstrated that over the life of a 6.4-mm diameter cathode, the operating voltage for a given flow rate and current varies by approximately $\pm 1.0-\mathrm{V}$. It should be noted that the fluctuations referred to here occur over many tens to thousands of hours.

The voltage-flow rate characteristics of two mechanically identical cathodes, AR6-A and AR6-B, at 1.25-A are presented in figure 2 . The spot-mode voltages were within $1.5-\mathrm{V}$ from unit-to-unit, and the

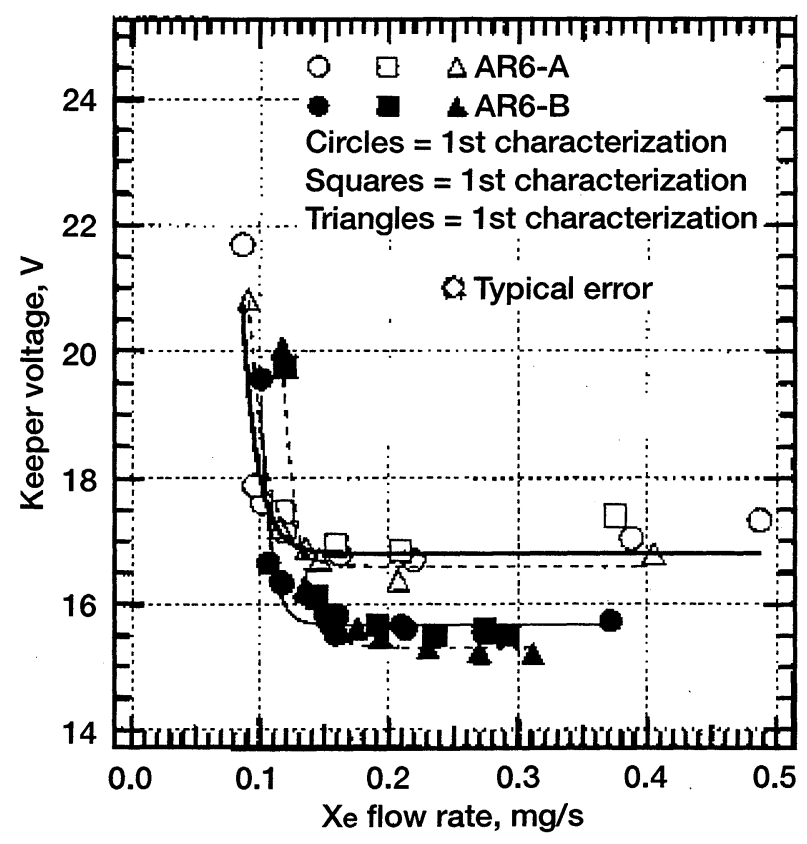

Figure 2.-Performance variance at 1.25-A for three mechanically identical hollow cathodes. 
transition flow rate varied by as much as $40-\mu \mathrm{g} / \mathrm{s}$. These variances were typical of those observed throughout the range of operating conditions evaluated. The keeper voltage fluctuations for individual cathodes were examined over the course of tens of hours and were found to be on the order of $0.2-\mathrm{V}$ when operated at constant current and flow rate. Inspection of figure 2 shows that the variance between subsequent characterizations was on the order of $0.2-\mathrm{V}$. The transition flow rate generally increased with time. This effect was attributed to an increase in the orifice diameter, and comparison of microscopic images of the orifice supported this conclusion. Given that similar fabrication and operating procedures were employed with both the 3.2-mm diameter hollow cathodes and the SSPCs, the variance exhibited in figure 2 was taken to be a reasonable representation of the performance variance expected with these cathodes. Consequently, the unit-to-unit voltage and transition flow rate variances were taken to be $\pm 1.4-\mathrm{V}$ and $\pm 25-\mu \mathrm{g} / \mathrm{s}$.

\section{Minimizing Power In a Diode Discharge}

Most of the experiments reported in this paper involved diode discharges between a hollow cathode and a keeper, and cathode power was defined as the product of the cathode-to-keeper voltage and current. By focusing on a diode discharge, comparison between the performance of the hollow cathodes was straightforward. This approach assumes that the total emission current, the sum of the keeper and secondary anode emission currents, dominates the conditions at the cathode, regardless of the distribution of the current to the anodes. The tests were conducted by varying the flow rate at constant current.

Figure 3 illustrates a typical performance characterization. The performance characterizations were conducted at intervals of several tens of hours of operation to obtain a more representative assessment of the cathode operating regimes than from a single characterization. Detailed information on the cathode performance appears in Domonkos, Gallimore, and Patterson (refs. 11 and 12). The portion of the curves where the voltage is only weakly dependent upon the flow rate is considered spot-mode. The power spectra of the spot and plume mode voltage for AR3-A appear in figure 4. The magnitude of the voltage oscillations appeared to be limited only by the output capability of the power supply. Analysis of the power

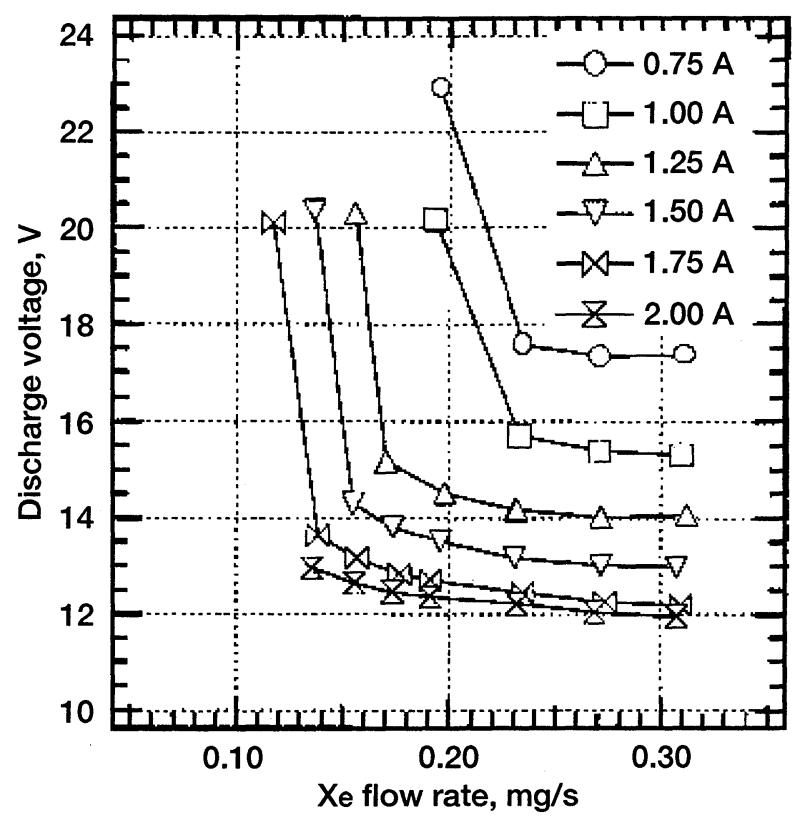

Figure 3.-Performance characteristics of AR1 after 60 hours of operation. 


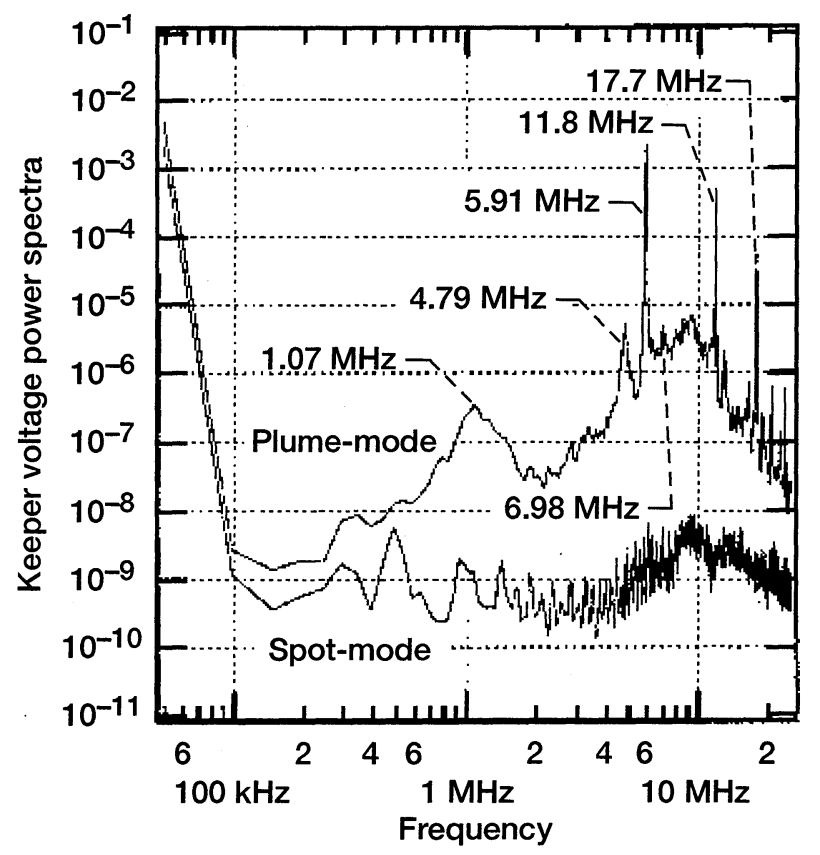

Figure 4.-High-frequency oscillations characteristic of plume mode.

spectra of the data in figure 4 revealed the absence of any dominant frequencies in the spot mode data, while the plume mode data exhibited prominent frequencies at several megahertz. The frequencies observed in plume mode were of the same order as the ion plasma frequency in the cathode-to-keeper gap (ref. 13).

As figure 3 shows, for a given current, a certain minimum flow rate is required to maintain spot mode emission. Cathode power consumption at the minimum flow rate condition for spot-mode emission is plotted as a function of the discharge current in figure 5. When comparing AR1, AR3-A, and AR6-B, the smallest aspect-ratio cathode consumed the least amount of power at a given current. While this result was expected since power scales with orifice length according to Ohms law, AR3-A and AR6-B operated at roughly equal power levels throughout the range of currents. This result suggests that the change in power consumption with orifice length occurs more rapidly at small aspect-ratios. The power consumption for AR1 was the lowest of all the cathodes tested. Changing the orifice diameter resulted in a negligible change in the power consumption as evidenced by figure 5. The use of an enclosed keeper reduced the power requirement on the order of 5 to 10 percent over the open keeper configuration. Since the enclosed keeper provides a superior radiation environment, the small improvement in power consumption by using the enclosed keeper suggests that conduction was the dominant heat transfer mechanism for the cathode tube; if the cathode were radiating strongly, the enclosed keeper would improve the performance more significantly than observed. The results of the thermographic investigations substantiate this finding and are presented later.

The flow rate required for spot mode emission, plotted in figure 6, also strongly influences efficiency in low-power thrusters. The model by Mandell and Katz (ref. 10) predicts that ion production within the orifice, and consequently ion flux out of the orifice, increase with orifice length for a given diameter and flow rate. As the orifice length is increased, the electron temperature in the orifice also increases due to Ohmic heating (ref. 10). The elevated electron temperature and increased channel length facilitate ionization. The transition to plume mode operation occurs when the ion production in and near the orifice is 


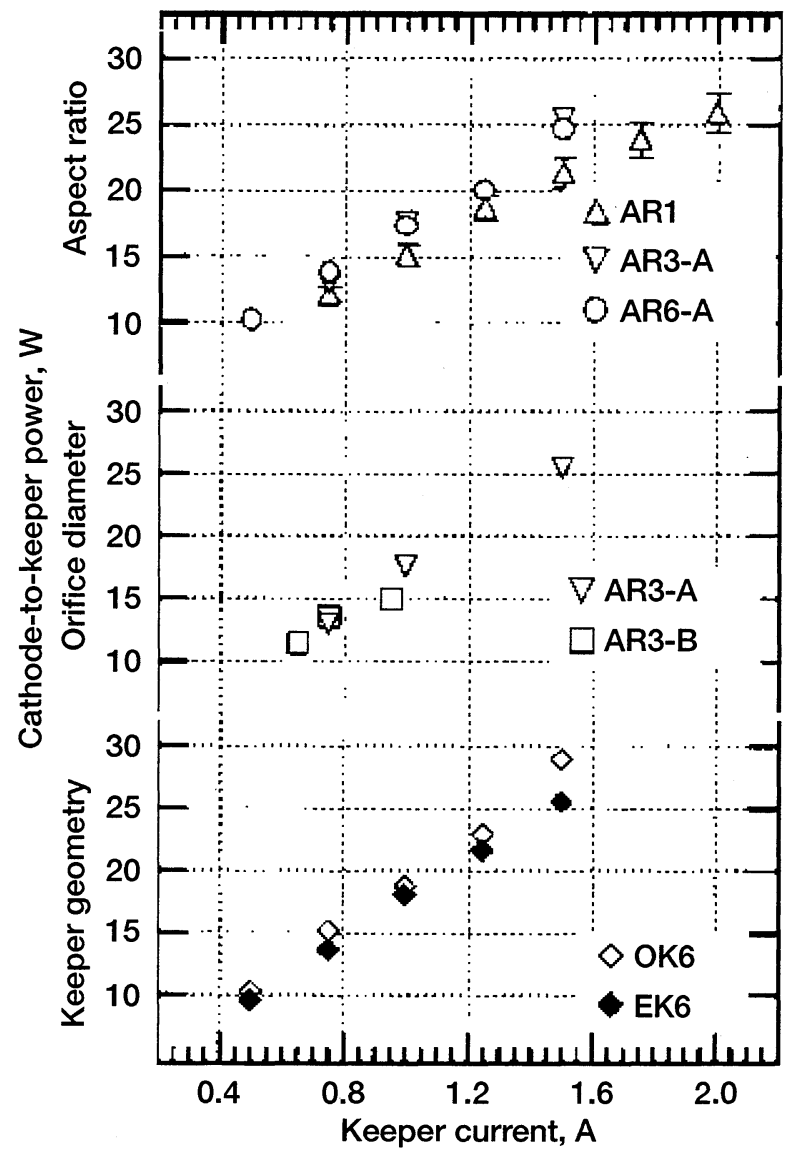

Figure 5.-Power consumption at the spot-mode minimum flow rate.

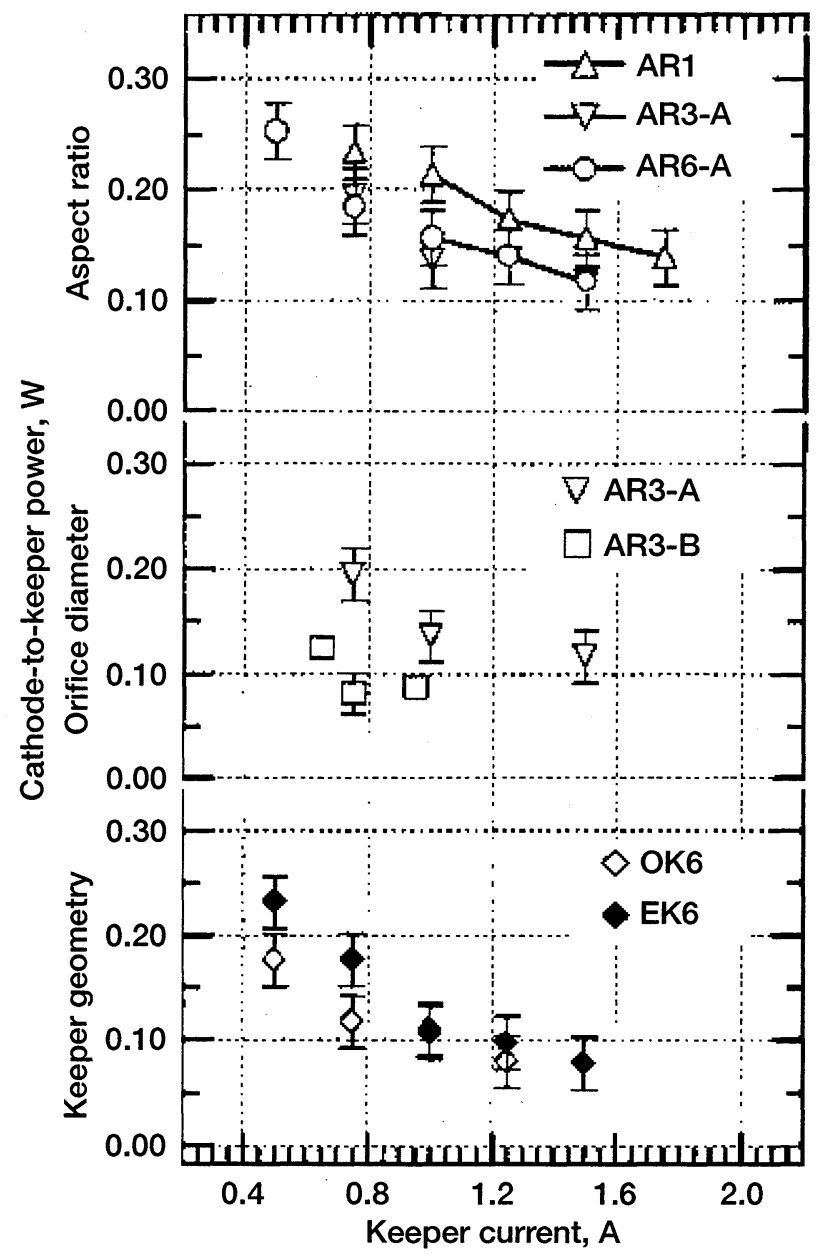

Figure 6.-Spot-to-plume mode transition flow rates.

insufficient to maintain charge neutrality in the cathode-keeper gap. Figure 6 shows that the model predictions were consistent with the trends observed for aspect-ratios between 1 and 6. The AR6-B and AR3-A cathodes appeared to transition at approximately the same flow rates, suggesting diminishing returns in optimizing the transition flow rate by increasing the orifice length. Indeed, one must also consider the ion losses as the orifice aspect-ratio is increased. The results in figure 6 demonstrated the expected trend that as orifice diameter decreases, the flow rate required for spot-mode operation also decreases. The increased current density within the orifice facilitates ion production and emission, maintaining the discharge. The transition flow rate was less for the open keeper configuration than for the enclosed keeper. This result suggests that the increased neutral density in the cathode-to-keeper gap of the enclosed keeper configuration leads to increased electron-neutral and ion-neutral collisions and impeded ion transport.

\section{Electron Emission Characteristics}

A secondary, planar anode $48 \mathrm{~mm}$ in diameter was placed $60 \mathrm{~mm}$ downstream of EK6 to assess the electron emission capability of the 3.2-mm diameter hollow cathodes. The flow was set to the minimum for spot-mode operation in a diode discharge, and the secondary anode was biased with respect to the cathode. The resulting characteristics are shown in figure 7 . Despite decreasing flow rates, the emission 


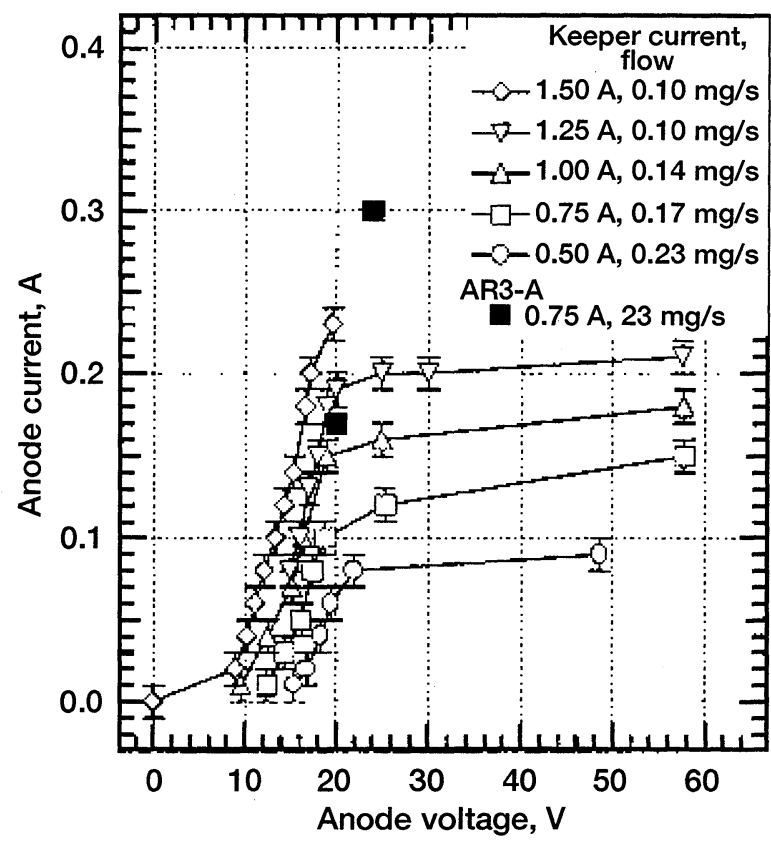

Figure 7.-Electron emission current for EK6 at several operating points exhibiting saturation at approximately $20-\mathrm{V}$.

current scaled with the keeper current. Additionally, current saturation appeared to set in at a bias of approximately $20-\mathrm{V}$. This result implies that the current conduction is predominantly a function of electron number density. Since the mesh keeper and orifice geometry were expected to contribute weakly to the change in emission current, the effect of increasing the flow at 0.75-A to the keeper was established; an increase of 35 percent flow rate increase led to a 100 percent increase in the emission current.

\section{Cathode Temperature Distribution}

By understanding the dominant heat transfer mechanisms, improvement of the cathode thermal isolation, and thereby power consumption, is facilitated. A model developed by Salhi (ref. 3) considered cathode operation in the limit of high power density where electron cooling was the only significant cooling mechanism. Since the focus of the present investigation was cathode operation in the limit of low-power density, additional cooling mechanisms were evaluated to determine their importance to the energy balance. A thermographic investigation was conducted to provide experimental data describing the significant heat transfer mechanisms at low-current.

\section{Thermographic Diagnostic Description}

The experimental procedures are summarized here, and a detailed description of the thermography diagnostic appears in Domonkos, Gallimore, and Patterson (ref. 14). An imaging radiometer scanned the infrared emissions from 8 to $12 \mu \mathrm{m}$. A close-up lens was used to enhance the resolution capabilities. Thermocouples were used to calibrate the radiometer output. The temperature distributions reported here are for a line parallel to the cathode axis. A slit was cut in the enclosed keeper so that the cathode surface temperature could be monitored. The slit width was approximately ten percent of the keeper diameter to permit the cathode surface to be viewed while minimizing the perturbation to the thermal environment. 


\section{Infrared Imagery Derived Results}

The degree to which the temperature profile deviates from linearity indicates the relative importance of radiation heat transfer with respect to conduction. Several of the temperature profiles acquired in this investigation are plotted in figure 8 , based on the coordinates illustrated in figure 1 . The data markers represent the calibration locations for the thermocouples. All of these data were taken in a diode discharge with the keeper. At $0.50-\mathrm{A}$, the shape of the profiles appeared similar upstream of the heater radiation shields. The enclosed keeper cathode operated approximately $100{ }^{\circ} \mathrm{C}$ warmer at the tip. The slopes and slope changes in the profiles for both the open and enclosed configurations are approximately equal beyond $-12 \mathrm{~mm}$ upstream. Estimates limited the radiative transfer to a peak value of $0.4 \mathrm{~W} / \mathrm{cm}$ of axial length at $-12 \mathrm{~mm}$, and the temperature drop along the length of the cathode limited the total radiative power to a few tenths of a Watt, typically. Calculations showed that the conductive heat loss was several Watts. Consequently, thermal conduction was found to be the dominant heat transfer mechanism in the upstream section of the tube at low-current. The resolution of the camera was insufficient to accurately determine the profile at the cathode tip. At 1.25-A and 1.50-A, the enclosed keeper upstream profiles were noticeably more linear than the open keeper distributions. By limiting the radiative transfer, the use of an enclosed keeper simplifies the problem of cathode optimization; minimizing the heat losses is accomplished by limiting thermal conduction. The profiles on the heater shield and the cathode tip temperatures followed the same trends as the upstream cathode tube temperature distribution throughout the range of currents tested. As is shown in the next section, the temperatures were weakly dependent upon on the flow rate, and the data presented in figure 8 were representative of the distributions at all of the flow rates tested.

\section{Tip Temperature Variations With Cathode Geometry}

A disappearing filament optical pyrometer with emissivity correction was used to determine the orifice plate temperatures. The variation of the orifice plate temperatures with geometry, current, and flow rate is presented in figure 9. The temperature was observed to scale in proportion with the aspect ratio. As the aspect ratio increases, the power loss in conducting current through the orifice also increases, leading to the observed temperature differences. A reduction in the orifice diameter led to a curtailed operating regime. The AR3-B cathode was limited to approximately two-thirds the maximum current of AR3-A. Figure 9(c) shows the orifice plate temperatures for EK6 and OK6 as a function of flow rate for three currents. In all cases the enclosed keeper operated at higher temperatures than the open keeper. Most of the data in figure 9 showed a slight increase in temperature at the onset of plume mode, the lowest flow rate for each curve. The contributing factors are the bombardment of the orifice plate by ions created in the cathode-keeper gap, and increased power deposition to the anode, thereby altering the thermal radiation environment.

\section{Discussion of Low-Current Hollow Cathode Applications}

Given the preceding presentation of the state of hollow cathode development, it is useful to consider the ways in which these cathodes fulfill the requirements of low-power electric propulsion systems. Ion thrusters in the 100 to $300 \mathrm{~W}$ range consume approximately 0.15 to $0.29 \mathrm{mg} / \mathrm{s}$ of xenon in the discharge chamber, while comparable Hall thrusters require 0.49 to $1.46 \mathrm{mg} / \mathrm{s}$ (ref. 15). In each case, the neutralizer flows of 0.08 to $0.25 \mathrm{mg} / \mathrm{s}$ in this study substantially reduce the specific impulse and efficiency, and the keeper discharge power consumes a more significant fraction of the total when compared to kW-class thrusters. Patterson and Oleson (ref. 1) have shown that a neutralizer cathode operating at and above $0.05 \mathrm{mg} / \mathrm{s}$ will reduce the efficiency of a $100-\mathrm{W}$ ion thruster by up to 30 percent. Additionally, the power 


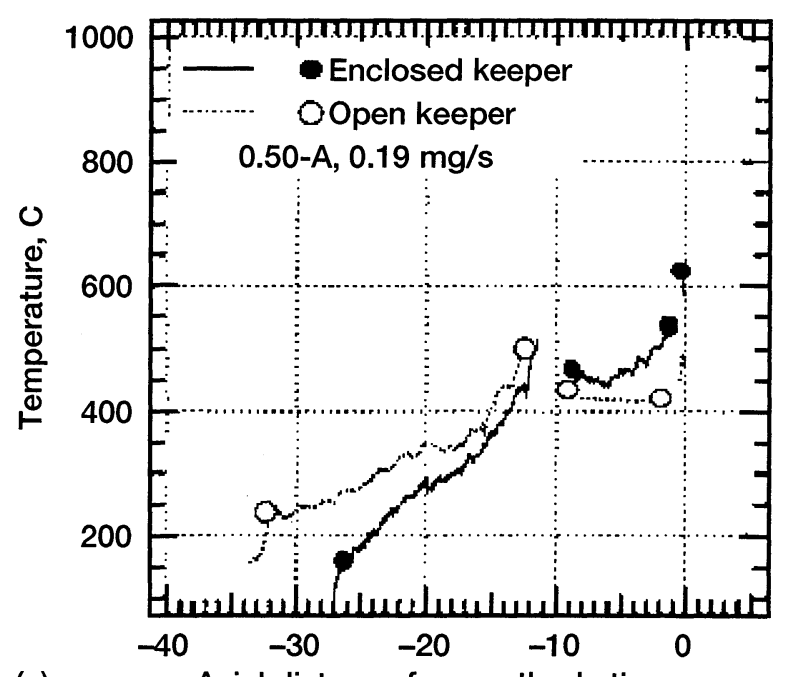

(a) Axial distance from cathode tip, $\mathrm{mm}$
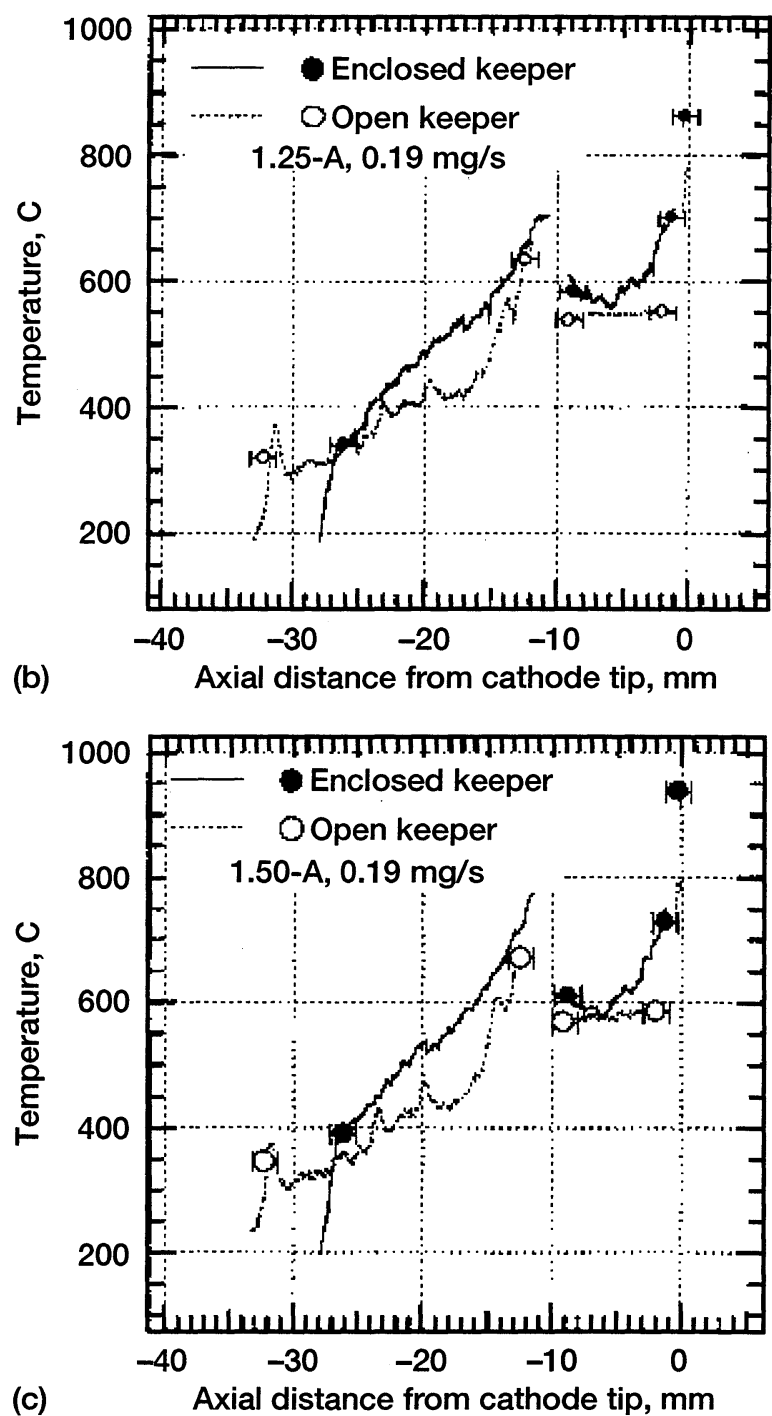

Figure 8.-Axial temperature profiles for the open and enclosed keeper configurations. (a) $0.50-A$ to keeper. (b) 1.25-A to keeper. (c) 1.50-A to keeper. 

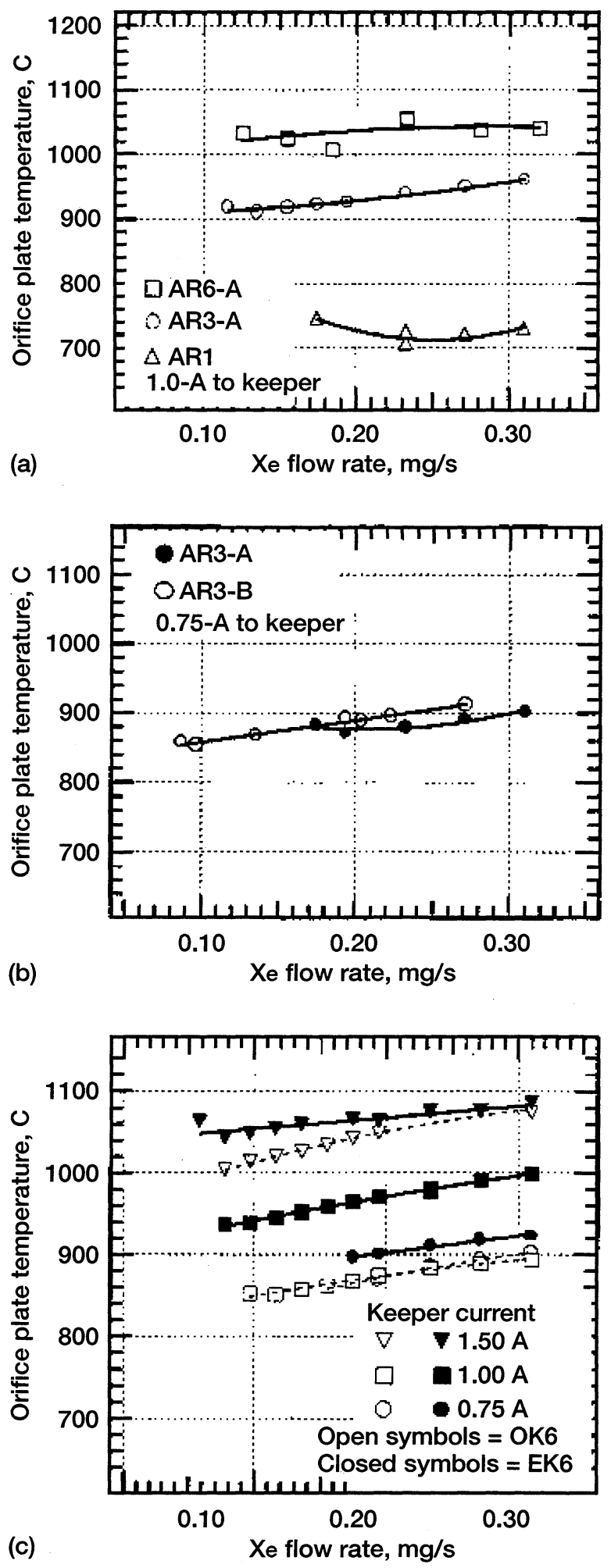

Figure 9.-Pyrometer observed orifice plate temperatures for several geometries. (a) Aspect-ratio dependency. (b) Orifice diameter dependency. (c) Keeper geometry dependency. 
consumed between the cathode and keeper is on the order of ten percent of the thruster power for the cathodes tested in this investigation. Hall thrusters may be operated without a keeper, mitigating the power loss in this discharge. When the emission current of the cathode is expected to be less than 1-A, such as the neutralizer for a low-power ion engine or the cathode for a sub-200-W hall thruster, operation with a keeper electrode may be necessary to sustain the discharge. The performance of the hollow cathodes tested in this investigation indicates the need for cathodes optimized for the low-power role. The findings of this investigation revealed that cathode optimization can be approached through the design of the orifice, keeper, and cathode tube.

\section{Conclusions}

This paper described an extensive experimental investigation targeting the operational and mechanical drivers which determine the effectiveness of hollow cathodes for low-power electric propulsion. Five separate 3.2-mm diameter orificed hollow cathodes were designed and tested in a number of different configurations. After establishing the performance variance between mechanically identical cathodes, power and expellant consumption were evaluated for several different orifice and keeper geometries. Power consumption increased with orifice length, while the minimum flow rate decreased. Both of these findings were predicted by the model described in reference 10 . The use of an enclosed keeper reduced the power consumption, however the minimum flow rate was observed to increase.

The behavior of the cathode external temperatures was also studied to determine the important heat transfer modes. Conduction dominated the heat transfer from the emission zone. The condition was more pronounced when an enclosed keeper was used. This conclusion means that cathode performance at lowpower can be readily improved by choosing materials with a low thermal conductivity for cathode construction.

\section{References}

1. Patterson, M.J. and Oleson, S.R., "Low-Power Ion Propulsion for Small Spacecraft," AIAA Paper No. 97-3060, 33rd AIAA/ASME/SAE/ASEE Joint Propulsion Conference, July 1997, Seattle, WA.

2. Siegfried, D.E., A Phenomenological Model for Orificed Hollow Cathodes, Ph.D. Dissertation, Colorado State University, 1983.

3. Salhi, A., Theoretical and Experimental Studies of Orificed, Hollow Cathode Operation, Ph.D. Dissertation, Ohio State University, 1993.

4. Rawlin, V.K. and Pawlik, E.V., "A Mercury Plasma-Bridge Neutralizer," Journal of Spacecraft and Rockets, Vol. 5, No. 7, July 1968, pp. 814-820.

5. Sarver-Verhey, T.R., "Extended Test of a Xenon Hollow Cathode for a Space Plasma Contactor," NASA CR-195402, Nov. 1994.

6. Sarver-Verhey, T.R., “28,000 Hour Xenon Hollow Cathode Life Test Results,” IEPC Paper No. 97168, 25th International Electric Propulsion Conference, Cleveland, OH, Aug. 1997.

7. Suitch, P.R., Thermochemical Reactions in Tungsten-Matrix Dispenser Cathodes Impregnated with Various Barium-Calcium-Aluminates, Ph.D. Dissertation, Georgia Institute of Technology, 1987. 
8. Patterson, M.J., Verhey, T.R., Soulas, G., and Zakany, J., "Space Station Cathode Design, Performance, and Operating Specifications," IEPC Paper No. 97-170, 25th International Electric Propulsion Conference, Cleveland, OH, Aug. 1997.

9. Kaufman, H.R., "Technology of Electron-Bombardment Ion Thrusters," Advances in Electronics and Electron Physics, Vol. 36, 1974, pp. 265-373.

10. Mandell, M.J. and Katz I., "Theory of Hollow Cathode Operation in Spot and Plume Modes," AIAA Paper No. 94-3134, 30th AIAA/ASME/SAE/ASEE Joint Propulsion Conference, Indianapolis, IN, June 1994.

11. Domonkos, M.T., Gallimore, A.D., and Patterson, M.J., "An Evaluation of Hollow Cathode Scaling to Very Low-power and Flow Rate," IEPC Paper No. 97-189, 25th International Electric Propulsion Conference, Cleveland, OH, Aug. 1997.

12. Domonkos, M.T., Gallimore, A.D., and Patterson, M.J., "Parametric Investigation of Orifice AspectRatio Effects on Low-Current Hollow Cathode Power Consumption," AIAA Paper No. 98-3345, 34th AIAA/ASME/SAE/ASEE Joint Propulsion Conference, Cleveland, OH, July 1998.

13. Domonkos, M.T., Operation of Low-Current Orificed Hollow Cathodes, Ph.D. Dissertation, University of Michigan, 1999.

14. Domonkos, M.T., Gallimore, A.D., and Patterson, M.J., "Thermographic Investigation of 3.2-mmDiameter Orificed Hollow Cathodes," AIAA Paper No. 98-3793, 34th AIAA/ASME/SAE/ASEE Joint Propulsion Conference, Cleveland, OH, July 1998.

15. Patterson, M.J., Grisnik, S.P., and Soulas, G.C., "Scaling of Ion Thrusters to Low-power," IEPC Paper No. 97-098, 25th International Electric Propulsion Conference, Cleveland, OH, Aug. 1997. 
Public reporting burden for this collection of information is estimated to average 1 hour per response, including the time for reviewing instructions, searching existing data sources, gathering and maintaining the data needed, and completing and reviewing the collection of information. Send comments regarding this burden estimate or any other aspect of this collection of information, including suggestions for reducing this burden, to Washington Headquarters Services, Directorate for Information Operations and Reports, 1215 Jefferson Davis Highway, Suite 1204, Arlington, VA 22202-4302, and to the Office of Management and Budget, Paperwork Reduction Project (0704-0188), Washington, DC 20503.

\begin{tabular}{|l|c|c|}
\hline 1. AGENCY USE ONLY (Leave blank) & $\begin{array}{c}\text { 2. REPORT DATE } \\
\text { July } 2002\end{array}$ & $\begin{array}{r}\text { 3. REPORT TYPE AND DATES COVERED } \\
\text { Technical Memorandum }\end{array}$ \\
\hline
\end{tabular}

\section{TITLE AND SUBTITLE}

Low-Current, Xenon Orificed Hollow Cathode Performance for In-Space Applications

6. AUTHOR(S)

Matthew T. Domonkos, Michael J. Patterson, and Alec D. Gallimore

\section{PERFORMING ORGANIZATION NAME(S) AND ADDRESS(ES)}

National Aeronautics and Space Administration

John H. Glenn Research Center at Lewis Field

Cleveland, Ohio 44135-3191

9. SPONSORING/MONITORING AGENCY NAME(S) AND ADDRESS(ES)

National Aeronautics and Space Administration

Washington, DC 20546-0001
WU-755-B4-04-00

5. FUNDING NUMBERS

8. PERFORMING ORGANIZATION REPORT NUMBER

E-13358

10. SPONSORING/MONITORING AGENCY REPORT NUMBER

NASA TM-2002-211574

\section{SUPPLEMENTARY NOTES}

Matthew T. Domonkos and Michael J. Patterson, NASA Glenn Research Center; and Alec D. Gallimore, University of Michigan, Plasmadynamics and Electric Propulsion Laboratory, Ann Arbor, Michigan 48109. Responsible person, Matthew T. Domonkos, organization code 5430, 216-433-2164.

\section{2a. DISTRIBUTION/AVAILABILITY STATEMENT}

Unclassified - Unlimited

Subject Category: 20

Available electronically at hittp://gltrs.grc.nasa.gov/GLTRS

This publication is available from the NASA Center for AeroSpace Information, 301-621-0390. 12b. DISTRIBUTION CODE

13. ABSTRACT (Maximum 200 words)

An experimental investigation of the operating characteristics of 3.2-mm diameter orificed hollow cathodes was conducted to examine low-current and low flow rate operation. Cathode power was minimized with an orifice aspect ratio of approximately one and the use of an enclosed keeper. Cathode flow rate requirements were proportional to orifice diameter and the inverse of the orifice length. The minimum power consumption in diode mode was $10-\mathrm{W}$, and the minimum mass flow rate required for spot-mode emission was approximately $0.08-\mathrm{mg} / \mathrm{s}$. Cathode temperature profiles were obtained using an imaging radiometer and conduction was found to be the dominant heat transfer mechanism from the cathode tube. Orifice plate temperatures were found to be weakly dependent upon the flow rate and strongly dependent upon the current.

\begin{tabular}{|c|c|c|}
\hline \multicolumn{3}{|l|}{ 14. SUBJECT TERMS } \\
\hline $\begin{array}{l}\text { 17. SECURITY CLASSIFICATION } \\
\text { OF REPORT } \\
\text { Unclassified }\end{array}$ & $\begin{array}{l}\text { 18. SECURITY CLASSIFICATION } \\
\text { OF THIS PAGE } \\
\text { Unclassified }\end{array}$ & $\begin{array}{l}\text { 19. SECURITY CLASSIFICATION } \\
\text { OF ABSTRACT } \\
\text { Unclassified }\end{array}$ \\
\hline
\end{tabular}

